\title{
The main conditions for the development of the teacher's professionalism in modern conditions
}

\author{
Igor Gaidamashko ${ }^{*}$, Igor Babichev², and Olga Zhikhareva ${ }^{3}$ \\ ${ }^{1}$ Moscow Institute of Radio Engineering, Electronics and Automation (Technical University), \\ Moscow, Russia \\ ${ }^{2}$ LLC "Children's and Youth sports school "Tennis-Park", Moscow, Russia \\ ${ }^{3}$ Volga Region State University of Physical Culture, Sport and Tourism, Kazan, Russia
}

\begin{abstract}
The article studies the development of the professionalism of a coach in children and youth sports. The main content is devoted to the definition of the main conditions for the professional development of a sports coach. Among these conditions: certain personal qualities of the coach, a constructive professional environment, a continuous process of professional development in the framework of special courses, seminars, master classes, etc. A sufficient level of the coach personal qualities development, namely: motivational and value qualities, creativity, reflection, empathy and strong-willed qualities of the individual. An important component of the children coach professional environment is an interaction with the parents of a young athlete in issues related to the system of training, education, development of personal qualities, the formation of constructive attitudes and psychological state. A positive impact on the process of professionalization of a coach, includes a positive psychological climate, an established exchange of experience in the team, an opportunity to receive methodological assistance from highly qualified specialists.
\end{abstract}

\section{Introduction}

Special attention is paid to the problems of professional development in Russian science. Two branches of psychology are actively studying this topic: labor psychology and acmeology. Besides, we can say that the psychology of professionalism is being formed into an independent branch of psychology since the 80 s of the last century.

The fundamental researches of such scientists as Derkach A. A., Druzhilov S. A., Zazykin V. G., Klimov E. A., Kuzmina N. V., Markova A. K. and many others are a serious basis for further research aimed at understanding the essence of professionalism as a scientific concept, conditions, factors, criteria, levels and stages of its formation and development among representatives of various professions.

The topic of children's and youth sports is actively researched in various countries of the world $[1,2,3,4,5,6]$.

\footnotetext{
* Corresponding author: gajdamashko@mirea.ru
} 
Despite the fact that in some works the issue of the coach professional development is discussed in sufficient detail [7], this topic is particularly relevant in view of the new challenges faced by the domestic sports industry: the notorious problem of doping, excessive commercialization of sports, a decrease in the competitive level of Russian athletes in some sports, etc.

Moreover, it should be noted that the problem of developing the coach professionalism in children and youth sports has not received proper coverage in modern science. Meanwhile, children and youth sports are the basis of the sports industry, since not only sports qualities (such as technical, tactical, physical) are formed in childhood but also qualities of a person necessary to achieve significant results in sports.

The profession of a coach in the system of children and youth sports, in our opinion, implies a significantly greater set of psychological and pedagogical competencies (for example, knowledge of the basics of developmental psychology and general pedagogy) than even the work of a coach in high-performance sports. It is primarily due to the greater educational role of a children coach, which largely determines the personal formation and development of an athlete.

In this regard, the topic of coach professional development in children and youth sports is extremely relevant and practically significant.

The purpose of this study is to determine the main conditions for the professional development of sports coaches.

\section{Results}

In general, modern science defines the concept of "professionalism" as a large set of elements that reflect the high productivity of professional activity [8].

Accordingly, we can say that the development of professionalism implies the development to some extent of all the elements of this set, and the criterion for the level of professional development can be, first of all, the level of productivity.

Most researchers dealing with the problem of professional development agree that the development of a professional's personality is carried out as a result of the systematic acquisition of new knowledge and the development of personal qualities necessary for the development of new professional skills and abilities. At the same time, it is noted that professional development should become a way of thinking of a specialist aimed at reaching the top of the profession. In addition, the criterion of true professionalism is the need for professional development of the individual throughout a person's life [9].

Thus, in the context of the study of the professional development problem, we can state that this development is of an endless nature, as well as the development of the personality itself. These processes are parallel and significantly interrelated.

It is no coincidence that the term "personal and professional development" has become stronger in modern science, meaning in a broad sense the process of formation and development of the individual and his professionalism, manifested in self-development, professional activity, professional relations, etc. One of the main components of professionalism is "professionalism of the individual» - a qualitative characteristic of the subject of work, reflecting a high level of development of professionally important and personal-business qualities, acmeological components of professionalism, an adequate level of claims, motivational sphere and value orientations aimed at the progressive development of a specialist [10].

Accordingly, we can say that the basis of continuous and effective professional development is the unsaturated human need for self-improvement: both personal and professional, as well as the focus on high professional achievements, due to a steady 
interest in the chosen profession and the same steady desire to achieve professional heights (fig. 1).

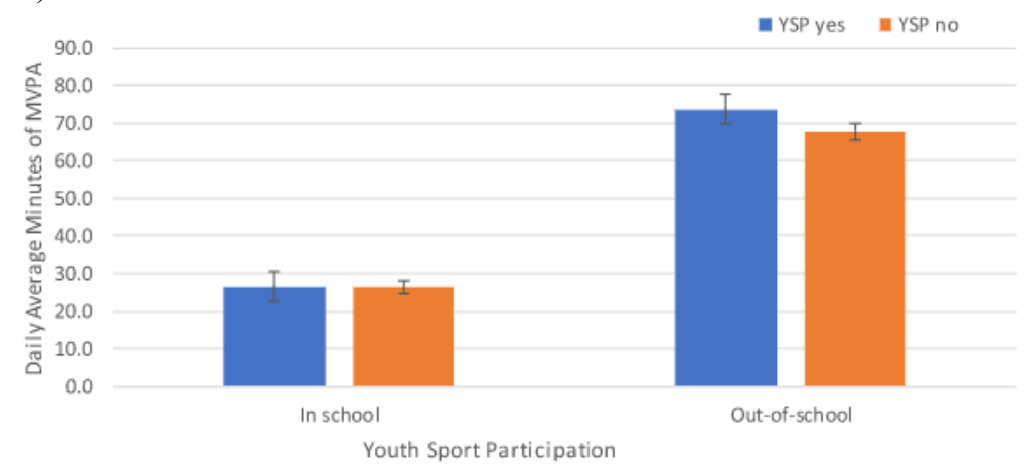

Fig. 1. Differences between youth sport participation and in-school and out-of-school daily average minutes of MVPA [1, p. 5].

On the one hand, these personality traits can be considered as professionally important qualities of a specialist, regardless of the field of professional activity, on the other hand, they can be considered as necessary conditions for professional development.

Such qualities of the subject of activity are defined in modern science as acmeological invariants of professionalism - the main qualities and skills of a professional that ensure high stable efficiency and reliability of the performed activity, almost regardless of its content and specifics.

On the one hand, acmeological invariants of professionalism as the main qualities and skills of a professional provide the opportunity to achieve professional heights, on the other hand, they directly affect professional development. They are "interwoven" into the structure of the main subsystems of professionalism and represent both a factor and a criterion for the development of professionalism, studying which it becomes possible to analyze the professional development of the individual [10].

Thus, we can consider a sufficient level of certain qualities development of the coach, taken as acmeological invariants of professionalism, as an important and necessary condition for professional development. Accordingly, one of the main tasks of our research is to determine the complex of these qualities.

According to V. G. Zazykin, general (independent of the activity type) acmeological invariants of professionalism are:

- developed anticipation, as the ability to predict, anticipate the development of situations in professional activity;

- a high level of self-regulation, as the ability to manage your condition, manifested in working efficiency, stress resistance, the ability to mobilize at the right time;

- ability to make timely and effective decisions;

- creativity, which manifests itself in a high creative potential and special skills to creatively solve professional problems;

- high and adequate motivation of achievements.

All these qualities, in our opinion, are extremely necessary for achieving a high level of professionalism in coaching.

Special studies allowed us to identify the corresponding acmeological invariants of professionalism for a coach, among which we can distinguish:

- developed strong-willed qualities;

- emotional stability, which is understood as immunity to emotionogenic factors. 
Based on the theoretical analysis and our own long-term experimental observations, we identify the following acmeological invariants of professionalism as necessary conditions for the development of coach professionalism:

- motivational and value qualities: the need for constant personal and professional selfimprovement, a high and adequate level of achievement motivation, a steady interest in the chosen sport, the need for professional communication (with mentees and colleagues);

- a sufficient level of creativity: a creative approach to solving professional problems, openness to new methods of training in sports, the ability to solve non-standard problems;

- developed reflection as the ability to adequately assess his own capabilities and achievements in the professional sphere;

- strong-willed personality traits;

- developed empathy, first of all, in relation to hismentees.

In our opinion, exactly these qualities of the coach personality are largely uncompensated and act not only as his professionally important qualities, but also as a kind of engine in the development of other equally important professional qualities, such as:

- developed self-regulation of mental states and activities;

- a sufficient level of psychological competence, which consists in knowing, first of all, the psychology of individual differences and the ability to apply them in practice, building an individual approach to the training of athletes, taking into account their psychological characteristics;

- communicative skills that allow you to build effective interaction with each individual athlete;

- anticipation, first of all, as the ability to predict the dynamics of the growth of the athlete's capabilities and his functional and psychological state at a certain point in time. Interesting data are given by Yabe, Y. et al, they are presented in table 1.

Table 1. Participants' baseline characteristics [4].

\begin{tabular}{|c|c|c|}
\hline Variables & Categories & $\mathrm{N}(\%)$ \\
\hline Sex $^{*}$ & Female & $4.931(75.9)$ \\
\hline Age (years) & Male & $1.552(23.9)$ \\
\hline & $<40$ & $2.711(41.8)$ \\
\hline $\begin{array}{c}\text { Educational attainment } \\
\text { her }\end{array}$ & $\geq 40$ & $3.754(57.8)$ \\
\hline & College or hig & $3.246(50.0)$ \\
\hline Working status $^{*}$ & High school or less & $3.227(49.7)$ \\
\hline & Unemployed & $1.212(18.7)$ \\
\hline Smoking habits $^{*}$ & Employed & $5.267(81.1)$ \\
\hline & Non-smoker & $4.793(73.8)$ \\
\hline $\begin{array}{c}\text { Number of years that their children } \\
\text { had been playing the present sports }\end{array}$ & Smoker & $1.660(25.6)$ \\
\hline (years) & & $809(12.5)$ \\
\hline & 1 to $<3$ & $2.718(41.9)$ \\
\hline & 3 to $<5$ & $1.752(27.0)$ \\
\hline & $\geq 5$ & $1.139(17.5)$ \\
\hline $\begin{array}{c}\text { Satisfaction with their children's } \\
\text { attitude towards sports activities }\end{array}$ & Satisfied & $5.611(86.4)$ \\
\hline & & \\
\hline & Unsatisfied & $866(13.3)$ \\
\hline
\end{tabular}




\begin{tabular}{|c|c|c|}
\hline $\begin{array}{c}\text { Experience playing the same sports } \\
\text { as their children }\end{array}$ & Absence & $4.575(70.5)$ \\
\hline $\begin{array}{c}\text { Experience playing on a team with } \\
\text { high levels of competition during }\end{array}$ & Presence & $1.900(29.3)$ \\
\hline $\begin{array}{c}\text { Their junior or senior high school } \\
\text { days }\end{array}$ & Presence & $3.991(61.5)$ \\
\hline $\begin{array}{c}\text { Experience of verbal abuse by their } \\
\text { own former coaches }\end{array}$ & Absence & $2.502(38.5)$ \\
\hline $\begin{array}{c}\text { Experience of physical abuse by their } \\
\text { own former coaches }\end{array}$ & Presence & $3.756(57.8)$ \\
\hline & Absence & $4.485(69.1)$ \\
\hline
\end{tabular}

*Because each item has a limited number of respondents, the actual number is not necessary in accordance with the total.

It should be noted that motivational and value qualities and developed reflection are largely the basis for the formation of a constructive "I-concept of a professional" in a specialist which is the most important personal education, acting both as a factor and a criterion for a high level of professionalism of the individual.

The following is important - the qualities of a coach, which we have identified as conditions for the development of his professionalism, can themselves reach a new, higher level of development during the professional development. At the same time, it is necessary to understand that without the initial sufficient level of these qualities development, it is difficult to predict the successful professionalization of a coach.

In addition to the necessary "internal" conditions for the development of the coach professionalism, by which we primarily mean a sufficient level of development of personal qualities that are acmeological invariants of professionalism, we also define a number of external conditions for the development of the coach professionalism.

It is necessary to include the presence of a constructive and developing professional environment into such conditions, first.

The influence of the environment on the development of personality in modern science is a global issue, and has been studied for many decades. The environment as a complex of factors that can influence a person, his development, formation, was realized in the V-IV centuries BC, in the time of Socrates, Plato and Aristotle [11]. There is no doubt about the significant positive or negative influence of the environment (social factor) on the development of the individual, along with the biological (hereditary) factor.

According to Voiko R. A., "the environment is subjective, the environment is where there is a person, accordingly, it is possible to use the influence of the environment on a person in managing the process of person development. In addition, we realize that the environment, from the point of view of the environmental approach, can act not only as a condition, but also, importantly, as a means of education and formation. The environment has the ability to cultivate a certain type of personality, as a subject of possessing the values of the environment, and who defines himself in the fact that he has something and is able to" [12].

All this is largely applicable to the professional environment, including the teaching environment. So, according to Tarkhan L. Z. and Savelyeva-Rat T. A.: "It is the educational environment that has the most significant impact on the professional and personal formation and development of the future teacher, making an early immersion into the professional environment, which provides favorable conditions for the disclosure of his creative abilities, subjectivity, self-affirmation in the relevancy of the teaching profession choice" [13]. 


\section{Discussion}

In the context of our research, it is important to reveal in detail the essence of the concept of "professional environment". A group of authors investigating the issue of the professional environment influence on the development of the civil servants professionalism defined the professional environment as a set of specialists who have special professional training and perform certain functions within the professional activities of the organization, as well as the conditions (material, social, informational, spiritual) for their professional activities [14].

This definition can only be partially accepted, as it applies only to certain types of activities that involve collective work within the same organization.

It should be noted that coaching activity can be carried out in different organizational and social conditions, which imply, first of all, a different level of autonomy of this activity.

In most cases, a children sports coach carries out his activities in children and youth sports schools or sports clubs in cooperation with other coaches with a sufficient degree of independence, under some supervision from the senior coach or sports director. In some sports, there are also coaches of a narrow profile, for example, a goalkeeping coach in football and hockey, or technical specialists (a mechanic in motorsport).

An important component of the children coach professional environment is the need to interact with the parents of a young athlete in issues related to the system of training, education, development of personal qualities, the formation of constructive attitudes and psychological state.

In addition, a coach, including children and youth sports, can actively interact with specialists in the field of sports medicine and psychology.

It is not uncommon for a children coach to carry out completely autonomous work, for example, leading a sports section at school or simply working with children outside of any structure of a sports school or tennis club. In this case, his professional environment is limited mainly to his students and their parents. At the same time, it must be recognized that this situation is more typical for mass sports, which in most cases do not involve high sports results.

In addition to the training process itself, coaching involves the participation of a coach in the competitive activities of hismetees. Accordingly, some interaction with referees, rival athletes, their coaches, and sometimes fans is added as components of the professional environment.

As it can be seen from all of the above, the professional environment of a coach is extremely diverse in terms of the possible components number, depending on the kind of sport and the degree of autonomy of a coach.

We can define the professional environment of a coach, first of all, as a set of interaction between all specialists and athletes involved in the training process and competitive activities, within certain conditions set by the specifics of a particular kind of sport, as well as indirect participants in sports activities: parents of athletes, spectators, fans, etc.

Accordingly, all the components of the professional environment identified by us can influence the development of the coach professionalism in a certain way, but, in our opinion, the most significant component of this environment is the interaction of a coach with other specialists in terms of the experience exchange, which is mostly possiblewithin the framework of collective activities. This is especially important at the initial stage of professional development of a sports coach who does not have sufficient work skills

It is obvious that the degree and nature of the environment influence on the development of the coach professionalism depends on the peculiarities and characteristics of this environment. 
The study conducted by the free interviewing methodof coaches of a children and youth sports school in tennis, whose mentees are members of the Russian youth national tennis team (in total 20 respondents participated, the experience of coaching from 5 to 10 years), allowed us to identify some of the most significant features of the professional environment that promotes professional development.

Thus, as conditions for effective professionalization, the majority of respondents noted:

- experience working together with a highly qualified specialist (for example, as his assistant);

- the opportunity to observe the activities of more experienced colleagues;

- the opportunity to receive practical and methodological recommendations from a senior coach or sports director in problematic situations;

- positive psychological climate in the team;

- the opportunity to share experiences in a friendly, informal setting.

It should be noted here that the interactions of subjects in joint activities reveal additional non-additive effects that change the simple sum of their activity. Thus, when working in a team, social facilitation can occur, when the presence of colleagues works as a stimulation and facilitation of the individual's activities, and leads to an increase in the productivity of his work [15].

On the other hand, combination of physical and social activity of people can have negative effects, such as a decrease in the productivity of an individual in a group, blocking the social activity of an individual (the Ringelman effect-a progressive decrease in the efforts of participants in proportion to the increase in the group), "group like-mindedness" a decrease in intellectual efficiency, distortion of reality assessments and moral qualities of group members; the negative consequences of an inadequate leadership style, etc. [ibid].

Our respondents note that the main factors that seriously hinder professional development are the presence of open and latent contradictions and conflicts in the team, primarily of a financial nature, excessive competition for the right to train the most promising athletes, lack of interest of administration in the quality (high level) of their professional activities, etc.

Thus, working in a team can have both a positive value for the development of the coach professionalism, and a negative value if the interaction with colleagues is mostly deconstructive.

Besides, we note that at a certain stage of the coaching career, the professional environment, which is initially constructive, can "slow down" the further development of the professionalism of a particular specialist. This can be caused, in addition to financial contradictions, by the difference between the tasks facing the sports organization (sometimes quite utilitarian), and the personal, more ambitious aspirations of a coach, which increase as he becomes more professional. In such a situation, it is appropriate to say that the further effective development of the coach professionalism presupposes changing the conditions of his professional environment.

Thus, our research allows us to draw the following conclusions:

- the professional environment is a significant condition for the development of the coach professionalism, especially at the initial stage of this development;

- for a positive impact on the process of professionalization of a coach, the environment must meet a number of requirements, including: a positive psychological climate, an established exchange of experience in the team, an opportunity to receive methodological assistance from highly qualified specialists;

- at different stages of the development of a coach professionalism, the features of the constructive professional environment may differ markedly. So, if at the stage of formation a coach needs some attention from more experienced colleagues and more 
normative activity, then at later stages he needs more autonomy and the opportunity to be creative in his work.

It should also be noted that with the professional development of a coach, the dependence of this development on the conditions of the professional environment can significantly decrease.

In addition to the peculiarities of the professional environment, in our opinion, an important condition for the development of the coach professionalism is the systematic improvement of skills in the framework of special training programs, courses and seminars

Here it is necessary to mention that coaching initially assumes the presence of higher pedagogical education, and, accordingly, basic knowledge of pedagogy, psychology, physiology and the theory of sports training.

Various studies on the problems of professional development of teachers point to the use of the advanced training institute as a necessary condition for this development $[16,17$, $18,19]$.

It is no coincidence that Article 34.3 of Federal Law No. 329-FZ of 04.12.2007 "On Physical Culture and Sports in the Russian Federation" prescribes the need to conduct advanced training courses for coaches at least once every four years.

It should be noted that advanced training courses can be considered not only as a condition for the development of the coach professionalism, but also as a form, and in many ways as a criterion for this development. By the way the coach treats this issue, you can judge the formation of his professionalism of the individual, which is expressed, first of all, in the desire for professional improvement.

\section{Conclusion}

Thus, as a result of the conducted research, we determined that the main conditions for the development of the coach professionalism in children and youth sports are:

1. A sufficient level of the coach personal qualities development, acting as acmeological invariants of professionalism, namely: motivational and value qualities, creativity, reflection, empathy and strong-willed qualities of the individual.

2. Constructive professional environment, especially at the stage of professional development.

3. Continuous process of professional development in the framework of special courses, seminars, master classes, etc.

\section{References}

1. D.K. Kellstedt, M.A. Schenkelberg, A.M. Essay, M.J. Von Seggern, R.R. Rosenkranz, G.J. Welk, R. High, D.A. Dzewaltowski, Archives of Public Health 79 (1), 46 (2021). DOI: 10.1186/s13690-021-00570-y

2. D. Jaf, M. Özdemir, T. Skoog, BMC Psychology 9 (1), 12 (2021). DOI: 10.1186/s40359-021-00522-9

3. L.V. Batalova, G.V. Merzlyakova, Teoriya i Praktika Fizicheskoy Kultury 2, 56-58 (2017).

4. Y. Yabe, Y. Hagiwara, T. Sekiguchi, H. Momma, M. Tsuchiya, K. Kanazawa, M. Koide, N. Itaya, S. Yoshida, Y. Sogi, T. Yano, T. Onoki, E. Itoi, R. Nagatomi, Tohoku Journal of Experimental Medicine 249 (4), 249-254 (2019). DOI: 10.1620/tjem.249.249

5. M. Radzimirska-Graczyk, W. Chalcarz, New Medicine 9 (2), 35-38 (2006). 
6. U.G. Longo, M. Ciuffreda, J. Locher, N. Maffulli, V. Denaro, British Medical Bulletin 120 (1), 139-159 (2016). DOI: 10.1093/bmb/ldw041

7. A.A. Derkach, A.A. Isaev, Pedagogical skill of the coach. Physical culture and sport (Moscow, 1981).

8. A.K. Markova, Psychology of professionalism. International Humanitarian Fund (Knowledge, Moscow, 1996).

9. I.R. Tofler, G.J. Butterbaugh, Clinics in Sports Medicine 24, 783-804 (2005). DOI: 10.1016/j.csm.2005.05.006

10. A.A. Buchek, A.V. Ermolenko, Bulletin of the Kemerovo State University 2, 73-76 (2016).

11. A.P. Khrienko, Thesaurus of Sociology. Thematic dictionary-reference guide (UNITY-DANA, Moscow, 2009).

12. C. Ryan Dunn, T.E. Dorsch, M.Q. King, K.J. Rothlisberger, Family Relations 65 (2), 287-299 (2016). DOI: 10.1111/fare.12193

13. J.A. Karvunis, L.V. Kapilevich, Teoriya i Praktika Fizicheskoy Kultury 10, 1-15 (2020).

14. L. Chekhovska, R. Turka, Journal of Physical Education and Sport 15 (3) 81, 538542 (2015). DOI: 10.7752/jpes.2015.03081

15. V.A. Tolochek, Modern psychology of labor (Piter, St. Petersburg, 2005).

16. I.V. Gaidamashko, A.G. Zazykin, E.V. Pugacheva, Psychological invariants of managers ' professionalism (Moscow, 2018).

17. I.V. Gaidamashko, E.M. Klimova, Professionalization of the individual at the stage of obtaining higher education, Human Capital 12-1, 57-63 (2020).

18. V.N.Panova, Education and upbringing 1 (27), 46-48 (2020).

19. A.J. Ross, C.J. Mallett, J.F. Parkes, International Journal of Sports Science and Coaching 10 (4), 605-622 (2015). DOI: 10.1260/1747-9541.10.4.605 